Journal of Thermal Engineering, Vol. 6, No. 6, Special Issue 12, pp. 354-368, December, 2020

Yildiz Technical University Press, Istanbul, Turkey

\title{
AUTOMOTIVE HEADLAMP HIGH POWER LED COOLING SYSTEM AND ITS EFFECT ON JUNCTION TEMPERATURE AND LIGHT INTENSITY
}

\author{
Ramesh Kumar Chidambaram ${ }^{1 *}$, Rammohan Arunachalam ${ }^{1}$
}

\begin{abstract}
Halogen bulbs are sources of light of headlamps of most of the vehicles running around the world. To get better night vision, vehicle owners want to replace the conventional halogen bulbs with HPLEDs without replacing the conventional headlamp assembly. Though High Power Light Emitting Diodes (HPLED) are efficient sources of light for replacing halogen bulbs, conventional headlamps are not designed for HPLEDs and so replaced HPLEDs will fail within a short duration due to poor cooling. The aim of this work is to develop a compact cooling system for a conventional headlamp assembly to accommodate HPLEDs. An air cooled system with a compact heat sink is proposed in this work. To decide the dimensions of the compact heat sink various heatsink sizes were modeled and simulated in ANSYS. For this study, a popular SUV's headlamp is chosen and complete tests were carried out in absence of external lights on a flat black surface for about 28 meters. The light intensity is measured in terms of lux for Halogen and HPLED's horizontal passing beam at various test points. For generating the same intensity of light, it was found from the experimental results that the HPLED consumes only one third of the energy supplied to halogen bulbs. With the proposed cooling system the junction temperature was reduced by about $25 \%$ when the cooling fan is operated at laminar flow conditions. On the other hand, the luminous intensity of the HPLED improved by about $30.9 \%$ due to the decrease in junction temperature. The HPLED headlamp reflector inner wall temperature is found to be $49 \%$ lesser than Halogen bulb headlamp reflector inner wall temperature.
\end{abstract}

Keywords: HPLED Cooling System, HPLED Junction Temperature, Headlamp Reflector Temperature, Halogen, Light Intensity

\section{INTRODUCTION}

The headlamp of an automobile is one of the most primary active safety systems and it has an impact on the aesthetic look of the vehicle as well. In general, the headlamps must produce adequate illumination and serve its liability during night time and at lower visibility driving conditions during winter. Till the last decade the primary source of light in automotive headlamps are halogen bulbs and Xenon bulbs. Halogen bulbs have tungsten filaments as a light source which possesses high electric resistance. Xenon bulbs are also called as high-intensity discharge (HID) bulbs and it does not have filaments. White light emerges from ionized gas inside the bulb when a high voltage is supplied. Halogen bulbs do not produce UV radiation and light up instantly when switched on, in contrast, HID lamp takes time for the gases inside the bulb to reach the required operating temperature and to provide full light intensity after it is being switched on. Halogen or incandescent bulb has an operating life of 5000 hours whereas HID (High-Intensity Discharge) lamps can be operated for about 3000 hours.

When halogen bulbs are powered, it generates both heat and visible light. Halogen bulbs operate at the lowest efficiency when compared to all other automotive light sources. This clearly states that most of the energy supplied to the bulb is converted into heat and only a meager part of the electric energy is converted into visible light. The dissipated heat from the halogen bulbs is transferred to reflector and bulb holder through conduction and to ambient through lens cover by radiation. Headlamps designed for halogen bulb doesn't require an effective cooling system as most of the heat generated is transferred by radiation from the filament. Controlling the surface temperature of the headlamp reflector may increase the life of the headlamps. Sousa et. al. attempted to control the headlamp reflector temperature using a liquid cooled heat exchanger and maintained the temperature around $100^{\circ} \mathrm{C}$ This paper was recommended for publication in revised form by Editor Dr. Hatice Mercan

${ }^{1}$ Automotive Research Center, Vellore Institute of Technology, Vellore-632014, India

*E-mail adress: crameshkumar@vit.ac.in

Orcid id: 0000-0002-7446-1948, 0000-0002-7359-6648

Manuscript Received 29 March 2019, Accepted 23 July 2019 
while operating with halogen bulb at high beam. Authors measured the reflector surface temperature using thermocouples under steady and unsteady state operating conditions. The coolant velocity around the headlamp reflector is measured using Laser Doppler Velocimetry [1]. It is stated that without a cooling system temperature of the reflector wall rises above $100^{\circ} \mathrm{C}$ with halogen bulbs.

Automotive industries are slowly replacing the light source of their vehicle headlamps with HPLEDs in place of conventional Halogen and Xenon bulbs (HID) due to the advantages provided by HPLEDs. HPLEDs operate at highest efficiency when compared to all other sources of automotive light. HPLEDs are compact, produce white light (day time light) and operates at lower power when compared to halogen and HID. With a proper cooling system, the average operating life of an HPLED is around a hundred thousand hours. The luminous efficacy of HPLED which is expressed in terms of lumen output per watt supplied was found out to be $160 \%$ more than the efficacy of the HID system. Due to the compact size, the junction temperature of an HPLED rises quickly when it is switched on. As overheating of junction could lead to a drop in luminance output and permanent HPLED failure, the junction temperature needed to be kept in control and heat should be dissipated properly using a cooling system. Finned copper or aluminum heatsinks which give away the heat to the surroundings by natural / forced convection and by radiation are very common in high power HPLED cooling system. Forced convection with a compact electric fan attached to the heatsink can control the HPLED junction temperature more effectively within the safe limits.

Chun-Jen Weng found the variation in junction temperature by simulating an HPLED package with various heatsink sizes and cooling conditions. The author investigated the different configuration of the GaN-based chip and compared the variation of thermal resistance with respect to cooling air velocity on each configuration using COMSOL [2]. The author found that faster cooling is achieved with higher air velocities. Tsai et. al. studied the thermal performance of the Chip on Plate (COP) package using a thermal resistance circuit (TRC) method through experiments and simulation studies. Authors found that under natural and forced convection conditions, only the junction-to-air thermal resistance varied with respect to air flow conditions but thermal resistance between the heatsink and aluminum substrate junction remained unchanged [3].

To keep the junction temperature within safe limits, various cooling systems were proposed and implemented in automotive headlamps. Eui-Dae Jung studied headlamps of an old car by replacing the halogen bulb with a customized HPLED bulb. With the help of heatsink, heat pipe and DC fan author optimized the thermal management through five different configurations. When compared to all 5 configurations the combination of the heatsink, heat pipe and fan resulted in lowest junction temperature. The author also proved that the junction temperature reduces by $10^{\circ} \mathrm{C}$ with the heatsink and $15^{\circ} \mathrm{C}$ when a heat pipe is included. Further, the temperature reduced by $19^{\circ}$ when a fan is additionally used along with the heatsink [4].

In another study, Kaya studied HPLED cooling system using a combination of a heat pipe, a multi-fin heatsink with a fan and a cooling system with a thermoelectric cooler (TEC). It was found that the integrated multifin heatsink along with a fan was the most effective cooling system for a 30W HPLED [5]. Jing Wang et. al. demonstrated an enhanced HPLED cooling module with the help of thermoelectric cooler (TEC). Air and water were chosen as coolants to cool the HPLED modules. HPLED modules are not directly mounted on TEC instead, air or water is cooled by TEC and it is circulated into the HPLED module. Authors investigated the cooling system performance at different simulated ambient conditions and observed the effect of TEC on junction temperature, forward voltage, and light output. Their result showed that HPLED junction temperature varied linearly with the increase in ambient temperature and when the ambient condition is maintained at between $60-65^{\circ} \mathrm{C}$, the junction temperature raised to $59.5^{\circ} \mathrm{C}$, and the respective light output was around 1607 lumen [6].

Using ANSYS software, Sokmen et. al. demonstrated the changes in the junction temperature by varying the cooling fin parameters under free and forced convection of HPLED. Further, an optimum cylindrical fin structure was suggested for cooling the HPLED efficiently. The analysis was carried with various ambient temperatures such as $25^{\circ} \mathrm{C}, 50^{\circ} \mathrm{C}$ and $80^{\circ} \mathrm{C}$ and at various HPLED power dissipations such as $0.5 \mathrm{~W}, 0.75 \mathrm{~W}, 1 \mathrm{~W}$ and $1.25 \mathrm{~W}$ respectively. The author confirmed that including an aluminum or copper plate behind the PCB at lower ambient temperature is adequate to operate the HPLED [7]. Using a high power COB (chip on board) HPLED, Badalan et. al. conducted a comparison study between the fluid flow assisted by an external source known as active 
cooling and using fluid motion with natural convection known as a passive cooling system- The author concluded that wherever be the application, HPLED requires an additional cooling system to operate efficiently [8].

Sufian et. al. investigated the dissipation of the heat energy from an HPLED array using piezoelectric fans.. The fans were arranged in two different configurations face to face and edge to edge focusing the HPLED array. The authors concluded that with dual fans, heat transfer is 2.3 times higher than a single fan with a noteworthy reduction in the thermal resistance with both the configurations [9]. The piezoelectric fans are expensive at the same time they are compact in size when compared to the conventional DC fan. Similarly, Singh et. al. used a piezoelectric fan to improve the heat dissipation from the HPLED. Using this piezoelectric fan author were able to reduce the size of heatsink without any compromise on the performance of the HPLED [10].

Han-Kuei Fu et. al. established a relationship between heat and power supplied using a simulation model and estimated the temperature distribution in an HPLED module. The thermal path of HPLED module with 3D simulation is carried out with the commercial software package COMSOL [11]. To validate the simulation results, the author used an infrared camera to capture the thermal images. Using a multi-chip HPLED module Mika and Aulis conducted experiments at an atmospheric temperature of $21^{\circ} \mathrm{C}$ to study the surface temperature of the module at a rated power of 15W. Further using FEM software, the temperature of the HPLED module, heatsink and HPLED chip junction are estimated [12].

Jing Wang et. al. performed both numerical and experimental investigation to study the performance of HPLED modules with various lengths of the heat pipe. Based on their simulation and experimental results, heat pipes with a length of $30 \mathrm{~mm}, 40 \mathrm{~mm}$ and $50 \mathrm{~mm}$ performed better along with heatsink. Using the results of the study authors were able to correlate the relationship between ambient temperature and junction temperature and at steady ambient conditions the relationship between input power and junction temperature. Authors also concluded that a simple natural convection cooling system will not be sufficient to cool the HPLED headlamps [13].

Yen-Fu Su et. al. performed light degradation tests of high power HPLED working at an ambient temperature of $50^{\circ} \mathrm{C}$. The author found that at steady ambient temperature the junction temperature of the HPLED reached $84.5{ }^{\circ} \mathrm{C}$ at rated power. The author used a thermocouple to measure the temperature and varied the copper sink length and thickness to improve the thermal performances [14]. Kelvin Shih compared the relative brightness of HPLED modules with and without a heatsink assembly. The author strongly concluded that majority of the HPLED manufacturers provide minimum information regarding the thermal behavior of their LEDs and at times datasheets provided by few manufacturers contain a plot between current and relative brightness at $25^{\circ} \mathrm{C}$ only [15].

An automobile with adaptive HPLED headlights use smart sensors to sense the speed of the car, turning angle of the steering wheel, and the yaw of the particular car. Based on the sensor output, the electronic control unit processes the sensor data and provides the required tilt angle to move the reflector assembly. This movement will help the driver to view the road based on steering angle conditions especially while driving in the hill stations. Similarly with the help of sensors, the HPLED changes its light beam intensity based on the ambient lighting conditions whereas the halogen or HID have only low or high beam projections. Today automotive lighting technology is attaining new heights with the introduction of new technologies like adaptive lighting system, HPLED, laser bulbs, headlamp diagnostics etc. These technologies help vehicle drivers in different driving environments. HPLED is considered to be a promising technology and in coming years we can witness its implementation in automobiles. From the above literature survey, it evident that the advantage of compact HPLED poses a challenge of effectively removing the heat from the HPLEDs as heat accumulation affects the luminosity output, chromaticity (color of the light) and life. So HPLED requires an effective cooling system to dissipate the heat generated during its operation. As per the literature, most of the study recommends air cooling because of simplicity and easy installation when compared to liquid cooling. This substantial need makes the headlamp designers implement an effective headlamp system using HPLED without compromising the space. The factory fitted HPLED reflectors are not much different from conventional halogen reflectors except that it has an additional specific lens on each HPLED array to focus the low and high beam. This work covers all thermal aspects of HPLED while replacing the conventional headlamp halogen bulb. ANSYS tool was used to find out the suitable heatsink and to position CREE HPLED on the selected heatsink surface. Based on the literature studied, it was found that most of 
the earlier work used simulations, bench top models and thermal images to verify the performance of cooling systems. The HPLED headlamp regulations such as ECE, SAE and AIS which are followed in a different country recommends the use of lux meter to measure light intensity (in terms of lux) in the direction of driver's view up to 28 meters from the headlight. In this work, all thermal measurements are made with the help of thermocouples fixed on the reflector and heatsink. Also, more importance was given for real time tests to measure thermal performances and AIS 010 regulations were followed to measure the light intensity of HPLED. Also, the experimental results will be helpful to HPLED thermal designers to choose an appropriate cooling system and also provide useful design considerations on the replacement of Halogen with HPLED.

\section{EXPERIMENTAL SETUP AND METHODOLOGY}

Two headlamp assemblies of TATA SUMO Victa a popular utility vehicle in India is selected for the study. These headlamps are fixed and positioned on a fixture at the same height from the ground and at the same distance between them as it is in the vehicle. To conduct experiments on the HPLED cooling system, CREE makes HPLED of 16 Watts capacity was used in each of the headlamps as a light source to get required illumination and the results are compared with the results of an original Halogen lighting system for benchmarking. In this proposed cooling system, a commercially available electronics cooling fan is used. The size of the heatsink is chosen with respect to the results of a simulation study carried out in ANSYS. Various profiles and sizes of the heatsinks were modeled and analyzed in ANSYS. Based on the space in the headlamp, a simple heatsink with better performance is chosen using ANSYS results. Only the result of flat heatsink simulation is discussed in the results and discussion part. After the simulation studies, the experimental study was continued with a compact fan and heatsink combination. Table 1 shows the specifications of the halogen and HPLED bulbs used in this work. To measure the light intensity of both halogen and HPLED systems, experiments were conducted at night in absence of other lights to avoid interference. The test points (TP) are marked on the road at a distance between 4 meters on each angle as shown in Figure 1.

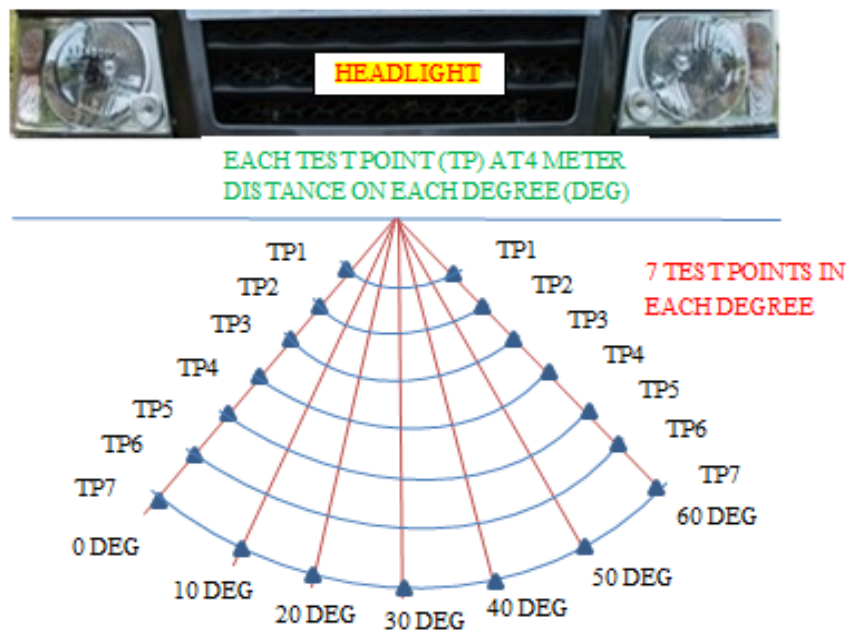

Figure 1. Test points for measuring light intensity using a lux meter

Markings were done for 60 degrees wide angle taking a center line drawn from the center of the two headlamps. Two lines are drawn at $30^{\circ}$ on both sides from this center line. For convenience left side $30^{\circ}$ line is taken as $0^{\circ}$ and right side $30^{\circ}$ angle line is taken as $60^{\circ}$. Seven lines were drawn from 0 to $60^{\circ}$. Seven test points were marked on each line at an interval of 4meters. Light intensity was measured at 49 points in terms of LUX using a LUX meter (LM100 Amprobe Light meter). Each test point is assigned a number in ascending order starting from the headlamp to extreme end of the line. During the experimental trials, halogen bulb was operated at $55 \mathrm{~W}$ with high beam and HPLED was operated at $16 \mathrm{~W}$. 
Table 1. Bulb specifications

\begin{tabular}{|l|l|l|}
\hline Specifications & Halogen Bulb & HPLED \\
\hline Manufacturer & Philips & CREE CXB1816 \\
\hline Power rating & $55 \mathrm{~W}$ & $16.2 \mathrm{~W}$ \\
\hline Voltage rating & $12 \mathrm{~V}$ & $36 \mathrm{~V}$ \\
\hline Current rating & $4.5 \mathrm{Amps}$ & $0.45 \mathrm{Amps}$ \\
\hline Cost & $10 \mathrm{USD}$ & $20 \mathrm{USD}$ \\
\hline
\end{tabular}

The junction temperature of the HPLED plays a vital role in its performance. According to the manufacturer note, to attain maximum efficiency, the junction temperature should be maintained close to $85^{\circ} \mathrm{C}$. $\mathrm{T}$ type thermocouples were used to sense the temperature at 12 locations inside the headlamp reflector assembly and on corners of the heatsink. The thermocouples used are capable of measuring the temperature range from $0^{\circ} \mathrm{C}$ to $760^{\circ} \mathrm{C}$. Using a Keysight data acquisition system and Microsoft Excel interface temperature is logged at a regular interval of 30 seconds and acquired data is used for the plotting. A regulated power supply is used to illuminate the bulbs and Voltage and current consumption was continuously monitored and recorded.

\section{Identification of thermocouple position on the heat sink}

As stated earlier, an analysis of heatsink shape and size for its optimization is carried out in ANSYS. Shape and size of the heatsink are optimized keeping the priority on heat dissipation and the space that is available in the headlamp assembly. For the requirement compactness, $1.2 \mathrm{~mm}$ thick flat heat sink made of aluminum was used for analysis. A study from the literature reveals that it is not necessary to use a finned heatsink when a cooling fan is used along with flat heatsink [7]. Moreover flat heatsinks are compact and save space in headlamps. A steady state thermal analysis using ANSYS is carried out with ambient temperature as $27^{\circ} \mathrm{C}$ and heat at source as $20 \mathrm{~W}$ capacity. A similar theoretical study was carried out by Maaspuro et. al.[12]. The analysis is carried out with HPLED mounted at the center of the heatsink plate to know the heat dissipation on the particular size heatsink as shown in Figure 2. Based on this temperature distribution, four hot spots were identified on heatsink and thermocouples were mounted on these points. After simulating the heat sink with HPLED at different locations, it was identified that placing the HPLED at the middle of the heatsink will dissipate the heat from HPLED uniformly and effectively in all directions. Colaco et. al. studied experimentally about the placement of HPLED at the center and concluded that HPLED will dissipate the temperature equally to all sides of heatsink [16]. The heatsink should have better thermal conductivity and good emissivity characteristics as together these properties effectively move the heat outside the HPLED package. Though, copper dissipates more heat, the cost of the copper heatsink is high when compared to aluminum.

As shown in Figure 3, $\mathrm{T}$ type thermocouples were pasted at the four corners and at the extension point of HPLED. These points are numbered as T1, T2, T3, T4 and TJ respectively. Thermocouples are also mounted on the inner, middle and outer periphery of the headlamp reflector. These points are numbered as T5, T6, T7, T8, T9, T10, T11, T12, T13, T14, T15 and T16 respectively as shown in Figure 3. With HPLED as a light source, 


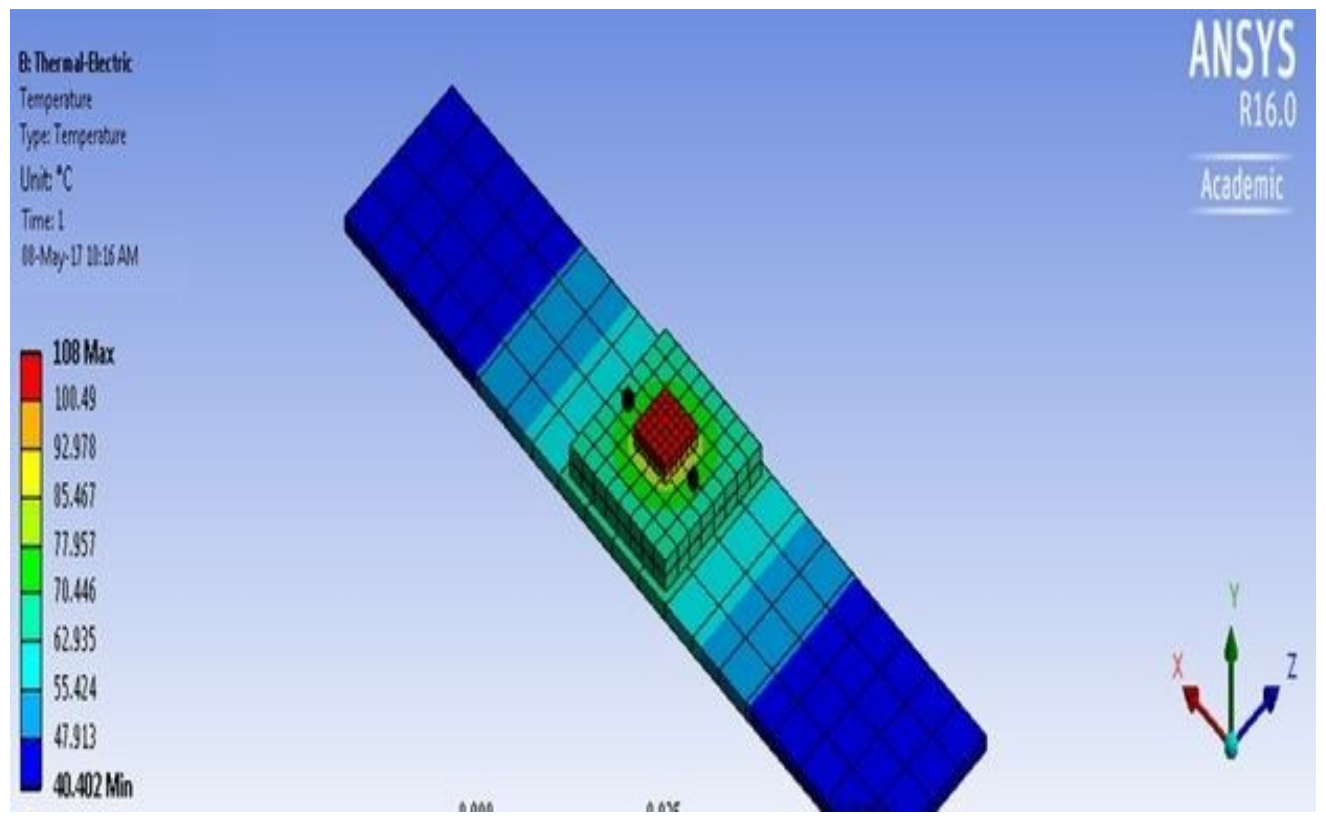

Figure 2. Temperature Distribution on Heatsink with HPLED

experiments were carried out when the HPLED is operated at rated power without switching on the cooling fan. Further, experiments were continued with a cooling fan operated from minimum to maximum power. The major limitation of the proposed working model is to maintain the HPLED junction temperature at $110^{\circ} \mathrm{C}$ maximum. The cooling fan must be operated at a required speed in order to maintain it.

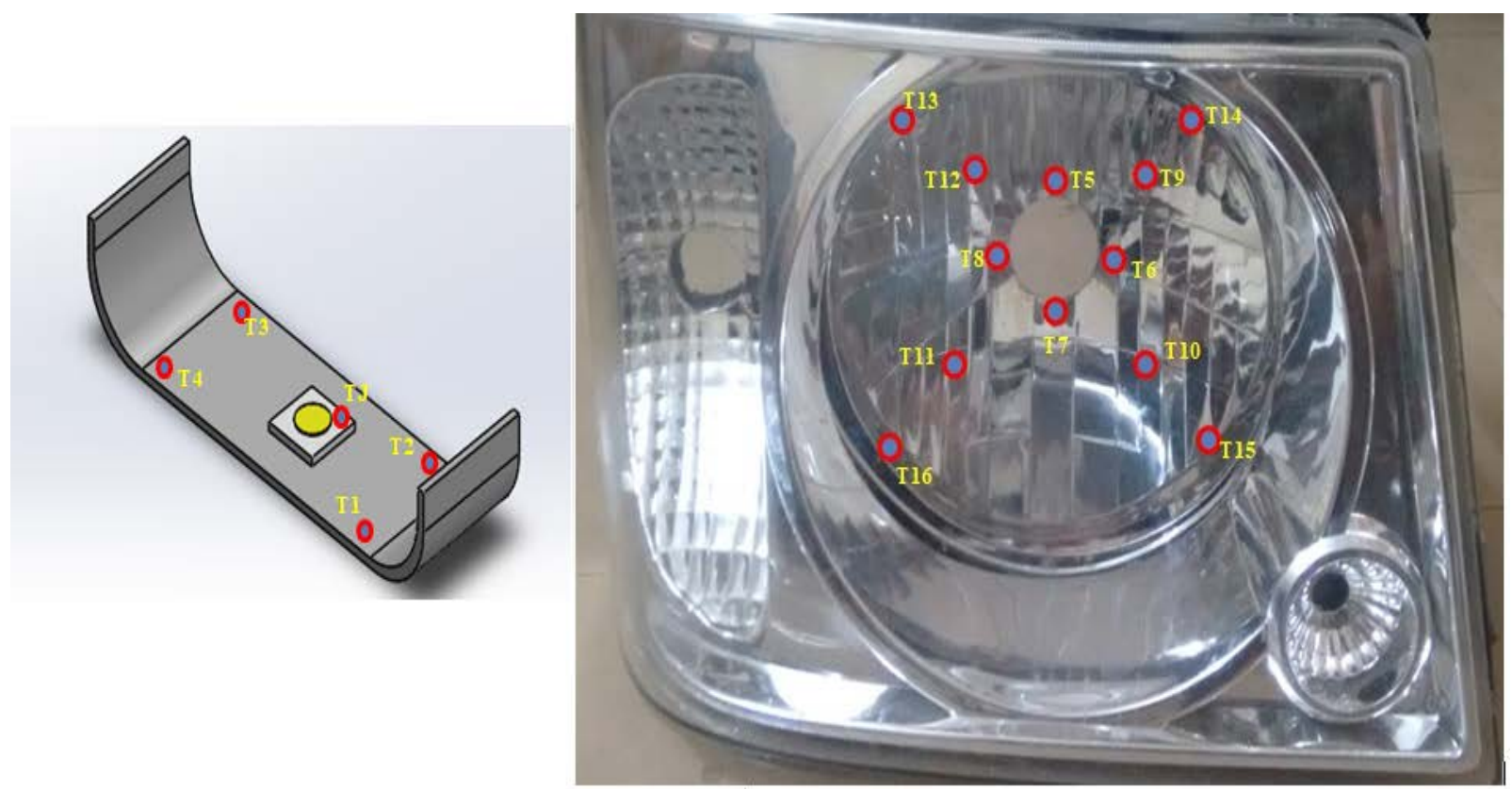

Figure 3. Thermocouple mounting positions in the heatsink and headlamp reflector

Figure 4 shows the experimental headlamp assembly used in this study with heatsink and cooling fan. The flow rate of air from the fan was measured using a hot wire anemometer. The error in the measurement of various quantities 
and propagation of these errors are computed based on the principle of root mean square method to get the magnitude of error [17]. The error in the temperature measurement and power measurement was obtained from Equation 1. The possible error in temperature measurement is around $0.056 \%$ and the percentage error in the computation of power supplied is calculated to be $0.18 \%$.

$$
\left(\frac{\partial T}{T}\right)=\left(\left(\frac{\partial T_{k-\text { type }}}{T_{k-\text { type }}}\right)^{2}+\left(\frac{\partial T_{\text {indicator }}}{T_{\text {indicator }}}\right)^{2}\right)^{\frac{1}{2}}
$$

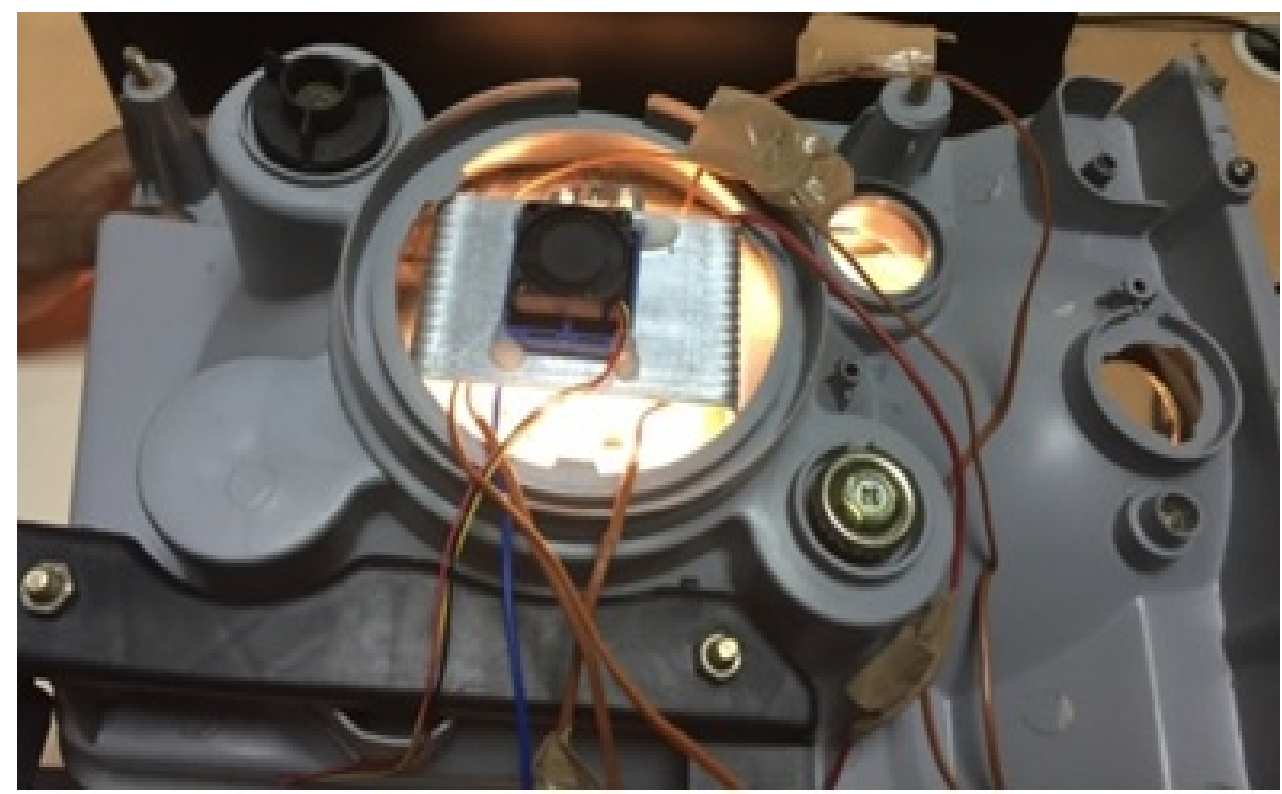

Figure 4. Headlamp assembly with heatsink and cooling fan

HPLED are not very efficient devices as electric energy given in is not completely converted into light output. Generally the HPLEDs have around 20 to 25\% efficiency and the rest of power is converted as heat. Considering 25 percent efficiency, the thermal heat output power $\left(\mathrm{P}_{\text {total }}\right)$ of HPLED is given by Equation 2.

$$
\begin{aligned}
P_{\text {total }} & =0.75 \times V_{\text {forward }} \times I_{\text {forward }} \\
& =0.75 \times 35.6 \times 0.45=12 \mathrm{~W}
\end{aligned}
$$

Dissipation of heat from HPLED depends on internal thermal resistance and heat sink thermal resistance. Internal thermal Resistance is a basic quality useful to determine HPLED's internal temperature and total heat dissipated. The thermal resistance model starting from junction to ambient is shown in Figure 5. The heat flows through the junction to solder point thermal resistance $\left(\mathrm{R}_{\mathrm{jn}-\mathrm{sp}}\right)$, solder point to printed circuit board thermal resistance $\left(\mathrm{R}_{\mathrm{sp}-\mathrm{pcb}}\right)$, a printed circuit board to thermal interface material thermal resistance $\left(\mathrm{R}_{\mathrm{pcb}-\mathrm{timl}}\right)$, thermal interface material to heatsink resistance $\left(\mathrm{R}_{\text {timl-hsk }}\right)$ and heatsink to ambient thermal resistance $\left(\mathrm{R}_{\text {hsk-amb }}\right)$. Thermal resistances given in Equation 3,4,5,6 and 7 can be defined as the ratio between temperature potential differences between the particular resistances and thermal input power $\left(\mathrm{P}_{\text {total }}\right)$. The total thermal resistance is the addition of all thermal resistances as given in Equation 8 and it will be useful to calculate the total thermal power and junction temperature theoretically. The internal thermal resistances given in the CREE datasheet is used to calculate the total junction to the ambient thermal resistance $\mathrm{R}_{\text {thcomp }}$ as $4.55^{\circ} \mathrm{C} / \mathrm{W}$. The total thermal resistance of CREE HPLED is not more than $10^{\circ} \mathrm{C} / \mathrm{W}$ at $105^{\circ} \mathrm{C}$ ambient condition. 


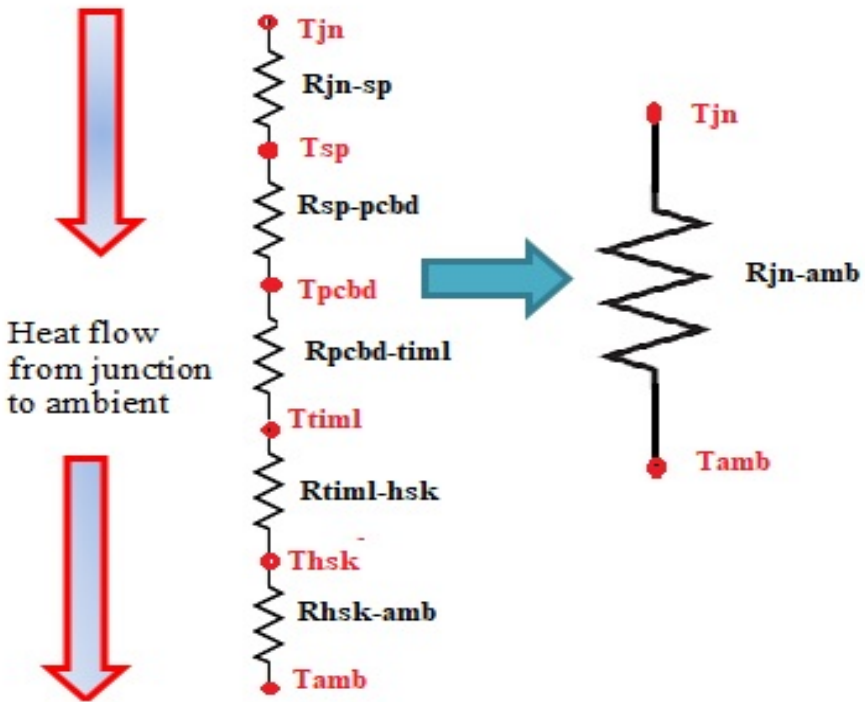

Figure 5. Thermal Resistance model of HPLED

$$
\begin{gathered}
R_{j n-s p}=\frac{T_{j n}-T_{s p}}{P_{\text {total }}} \\
R_{s p-p c b d}=\frac{\mathrm{T}_{\text {sp }}-\mathrm{T}_{\mathrm{pcbd}}}{\mathrm{P}_{\text {total }}} \\
R_{\text {pcbd-timl }}=\frac{\mathrm{T}_{\mathrm{pcbd}}-\mathrm{T}_{\text {timl }}}{\mathrm{P}_{\text {total }}} \\
R_{\text {timl }-h s}=\frac{T_{\text {timl }}-T_{h s}}{P_{\text {total }}} \\
R_{h s-a m b}=\frac{T_{h s}-T_{\text {amb }}}{P_{\text {total }}} \\
R_{\text {thcomp }}=R_{\text {jn-sp }}+R_{s p-p c b d}+R_{\text {pcbd-timl }}+R_{\text {timl }-h s}+\mathrm{R}_{\mathrm{hs}-\mathrm{amb}}
\end{gathered}
$$

As it is difficult to measure the junction temperature of HPLED directly, solder points of the HPLED are chosen as an ideal place to study junction temperature. Thermocouples are placed on the solder points provided on the package. The measured temperature from the solder points may not exactly give the junction temperature due to radiative conduction and convection losses. Equation 9 is used to calculate the junction temperature using thermal resistance.

$$
T_{j n}=T_{s p}+\left(R_{\text {thcomp }} \times \mathrm{V}_{\text {forward }} \times \mathrm{I}_{\text {forward }}\right)
$$

The Reynolds number is a dimensionless parameter that is used to calculate the ratio of inertial forces versus viscous forces and describes the air flow type such as laminar, transition or turbulent. The Reynolds number can be calculated from the following Equation 10 [18].

$$
R_{e}=\frac{\rho v l}{\vartheta}
$$

Where $\mathrm{v}$ is the velocity of the air in $\mathrm{m} / \mathrm{s}, \rho$ is the density of the air in $\mathrm{kg} / \mathrm{m}^{3}, \mathrm{l}$ is characteristic length or chord width in $\mathrm{m}, \vartheta$ is dynamic viscosity of the air in $\mathrm{Ns} / \mathrm{m}^{2}$. 


\section{RESULTS AND DISCUSSION}

First the performance of the headlamp fitted with the halogen bulb is studied without any cooling system. The experiments were continued with HPLED with and without cooling system and both the results are compared to analyze the merits of HPLED and its cooling system.

\section{Performance of Halogen bulb and HPLED based on light intensity}

The intensity of the light from both the bulb is measured and analyzed in this section. It is known fact that HPLEDs operate at a higher efficacy around $100 \mathrm{~lm} / \mathrm{W}$ than halogen bulbs, which is around $15 \mathrm{~lm} / \mathrm{W}$. A 16 Watt HPLED will be capable of producing light intensity much better than a 55Watts halogen bulb. Initially, a study was carried out using 5W and $10 \mathrm{~W}$ HPLEDs to match the light intensity of 55W halogen bulb. It was observed from the test points that the light intensity is not sufficient enough whereas the light output of 16 W HPLED was found to be matching and marginally better when compared with the light intensity of halogen. So a 16 W HPLED was chosen for this study. During the tests, temperature, the light intensity at all test points (TP), voltage and current values are recorded continuously until the values reach steady state conditions. Figure 6 shows the plotted values of light intensity at various test points such as TP1, TP2, TP3 and TP4 on each degree. Based on this test, it is observed that up to 16 meters of distance from the headlamp, the HPLED light output is better than the halogen. From the experiments and related plot shown in Figure 6, the highest light intensity is recorded at 30th degree which is the exactly middle line in between the headlamps as defined in section 2. It is also observed that, the light intensity of HPLED is 30 to $40 \%$ better than halogen bulbs at test points TP1, TP2, TP3, TP4 and it is marginally lower at test points TP5, TP6 and TP7. It is possible to achieve better or equal light intensity at these points by adjusting the focal point of the reflector cup in the headlight. According to AIS 010 regulation, passing beam light intensity of headlamps should be less than 290 lux for halogen headlamps and less than 365 lux for HPLED headlamps. The minimum light intensity requirement is 2 lux for both halogen and HPLED bulbs. From the experimental results, it is observed that the light intensity is about 385 lux for HPLED and 274 lux for halogen bulb at 4 meters which is marginally higher than the standard. Also, it was found that at 28 meters from the light source the minimum intensity values are 1.5 lux for halogen and 3 lux for HPLED. The values of the measured light intensity and power consumption of both HPLED and halogen bulbs help us to decide to switchover or replace the conventional halogen bulb with LEDs in halogen headlamp assemblies. It is also worth to mention here that the electric power consumption can be brought down by around $39 \mathrm{~W}$ in each headlamp with LEDs.
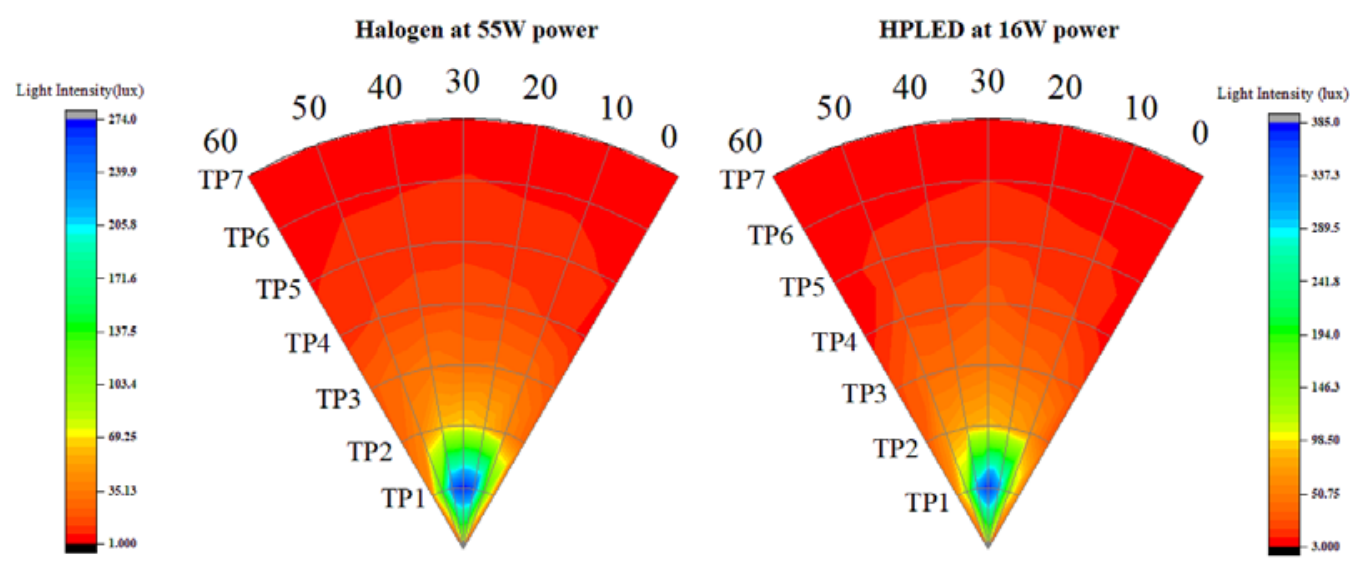

Figure 6. Light intensity in lux for a Halogen bulb and HPLED

\section{Performance of cooling system based on junction temperature}

In this section performance of the cooling system is analyzed based on variation in the junction temperature at various test points with respect to change in air velocity. In order to measure the variation in the junction temperature, the HPLED was initially operated at rated power with heatsink and without switching on the 
fan $[7,11]$. The junction temperature of the HPLED reached $116^{\circ} \mathrm{C}$ after 3 hours of duration and the experiment was stopped as prolonged operation above this temperature may lead to permanent failure. Further, the experiment was continued with the fan switched on. At minimum fan power, the air flow rate was found to be $1.6 \mathrm{~m} / \mathrm{s}$. At same room temperature and HPLED rated power, junction temperature reaches $104^{\circ} \mathrm{C}$ after 3 hours of duration with a cooling fan as shown in Figure 7. As shown in table 2, the fan was operated at different flow velocities $1.5 \mathrm{~m} / \mathrm{s}, 1.6$ $\mathrm{m} / \mathrm{s}, 1.7 \mathrm{~m} / \mathrm{s}, 1.8 \mathrm{~m} / \mathrm{s}$ and $1.9 \mathrm{~m} / \mathrm{s}$ and the corresponding observed junction temperatures are $104^{\circ} \mathrm{C}, 101^{\circ} \mathrm{C}$, $93^{\circ} \mathrm{C}, 90^{\circ} \mathrm{C}$ and $87^{\circ} \mathrm{C}$ respectively. After completing the tests at every velocity point, HPLEDs are switched off until it reaches ambient temperature.

Table 2 Variation in Junction temperature due to the air flow rate

\begin{tabular}{|c|c|c|}
\hline Air Flow rate (m/sec) & Junction Temperature $\left({ }^{\circ} \mathbf{C}\right)$ & Reynolds Number \\
\hline $\begin{array}{c}\text { Heatsink without } \\
\text { fan }\end{array}$ & 116 & - \\
\hline $\mathbf{1 . 5}$ & 104 & 2482 \\
\hline $\mathbf{1 . 6}$ & 101 & 2647 \\
\hline $\mathbf{1 . 7}$ & 93 & 2813 \\
\hline $\mathbf{1 . 8}$ & 90 & 2978 \\
\hline $\mathbf{1 . 9}$ & 87 & 3143 \\
\hline
\end{tabular}

It is observed from the study that for the given ambient temperature condition $27^{\circ} \mathrm{C}$, the fan has to be operated at $1.9 \mathrm{~m} / \mathrm{s}$ to maintain the HPLED junction temperature around $85{ }^{\circ} \mathrm{C}$. The HPLED manufacturer recommends maintaining the junction temperature bellow $85{ }^{\circ} \mathrm{C}$ to attain maximum luminous flux. In an actual vehicle, engine compartment temperature will be higher than the actual ambient temperature as engine rejects a lot of heat and we may require a bigger size cooling fan. In this study engine compartment temperature is not considered. The maximum engine compartment temperature was measured to be around $50^{\circ} \mathrm{C}$ at $27^{\circ} \mathrm{C}$ ambient condition when the vehicle is not moving. Figure 7 shows the variation of junction temperature with respect to time at different air velocities. Without a cooling fan HPLED junction temperature attains maximum of $116^{\circ} \mathrm{C}$ and the junction temperature reduces to $87^{\circ} \mathrm{C}$ when the fan blows air at a velocity of $1.9 \mathrm{~m} / \mathrm{s}$. Around $25 \%$ drop in junction temperature was achieved with a cooling fan. At $1.9 \mathrm{~m} / \mathrm{s}$ air velocity Reynolds number is calculated to be 3143 .

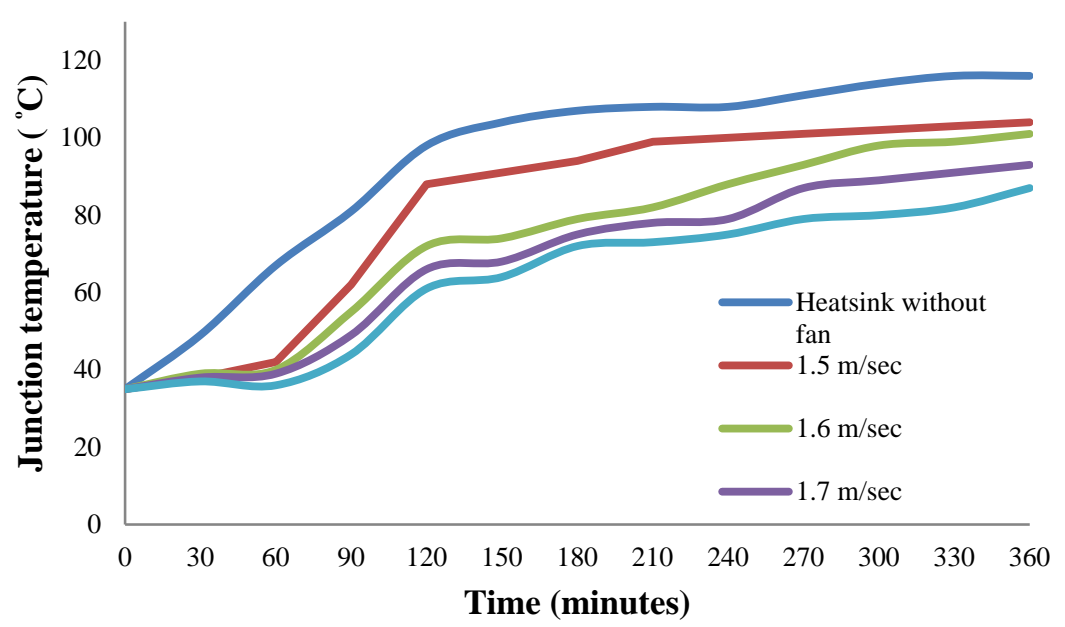

Figure 7. Junction temperature variation with a change in air flow rate or velocity 
The air flow regime based on the Reynolds number mentioned in Equation 12 is shown in Figure 8. It is decided to analyze the illumination values of TP1 at $30^{\circ}$ angle to study the impact of cooling air flow rate on light output as this test point achieves the highest illumination when compared to all other test points (TP). Figure 9 shows the variation of junction temperature and light output at TP1 with respect to air velocity.

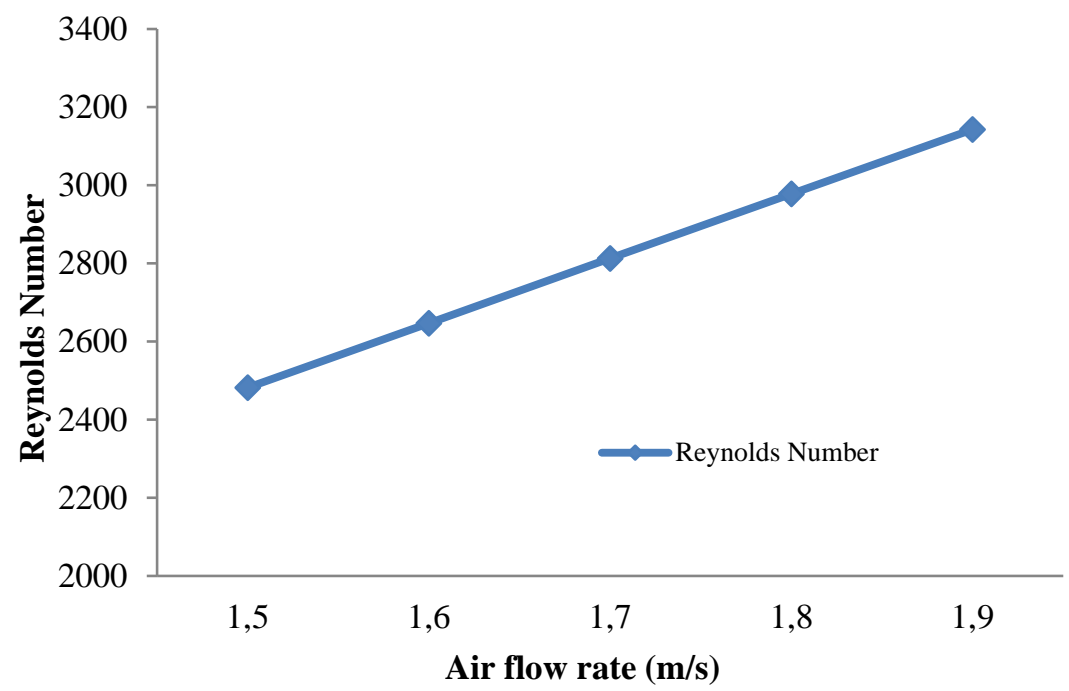

Figure 8. Air flow regime based on reynolds number

When the air flow regime is changed from laminar to transitional the junction temperature was observed to be reduced by $25 \%$ and at the same time luminous intensity increased by about $30.94 \%$. From the Figure 9, based on lumen difference $(\Delta \mathrm{lm})$ and junction temperature difference $(\Delta \mathrm{Tjn})$ we also can conclude that for every degree drop in junction temperature luminous intensity improves by $2.7 \mathrm{lux} /{ }^{\circ} \mathrm{C}$.

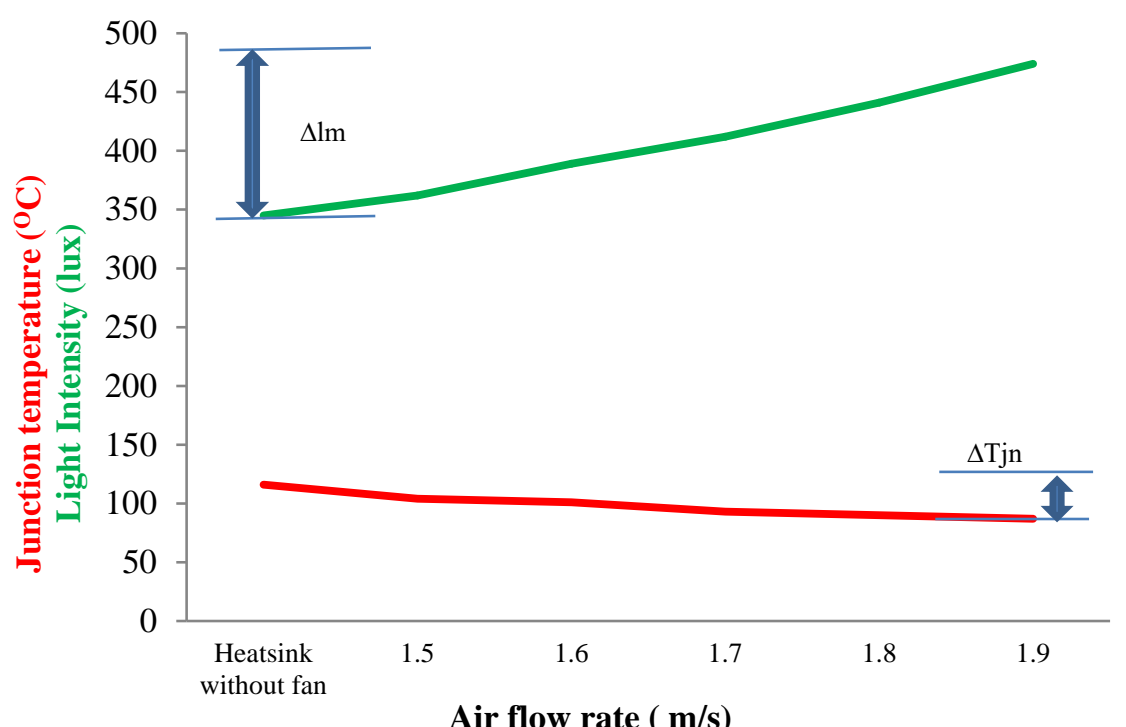

Figure 9. Junction temperature and Light intensity variation wrt air flow rate 
HPLEDs discharge different colors based on the HPLED material used at the junction by different manufacturers. The change in the color is usually measured in terms of correlated color temperature (CCT) in Kelvin. The average correlated color temperature of CREE HPLED varies from 3300 to $5500^{\circ} \mathrm{K}$ depending on junction temperature. Based on CCT value, the relative color output or shift will be decided under the category of white light, yellow (warm white) or blue (cool white). During the experimentation, the correlated color temperature was measured using Elma 1336 Chroma meter with respect to change in heat sink air flow as TP1 at 30 degrees the test point which receives the maximum light fall from the headlight as mentioned in the earlier sections. Figure 10 shows the change in the correlated color temperature with respect to junction temperature. According to the kelvin color temperature scale chart the range of 5200K of CCT is usually considered as natural white[19]. In automotive lighting, one of the major advantages of using HPLED its light output similar to day light.

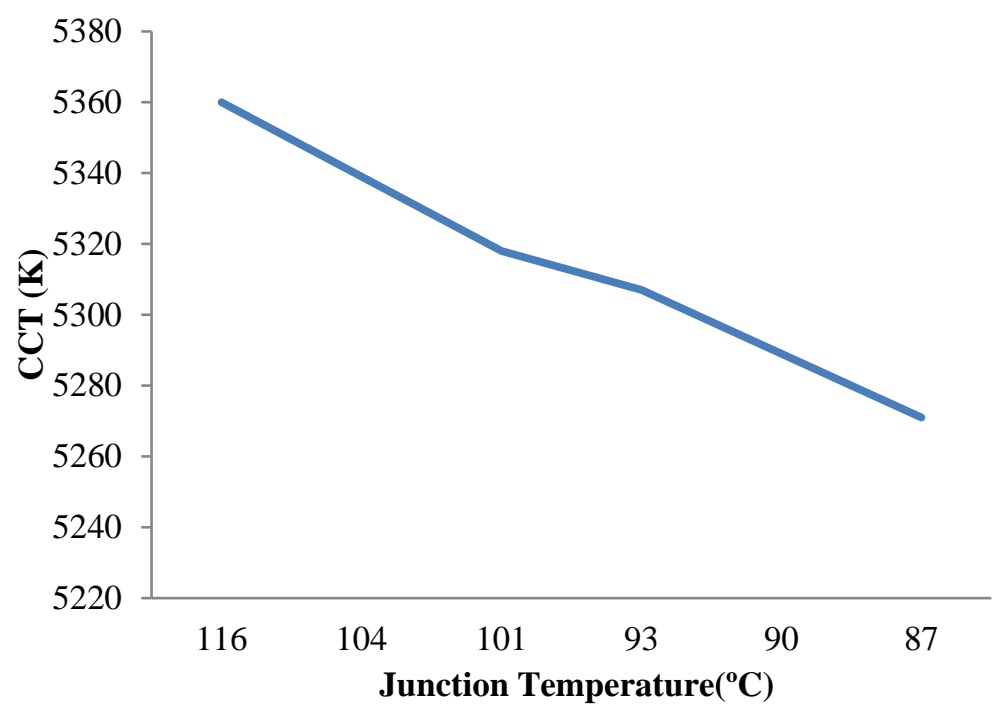

Figure 10. Junction temperature with respect to the color temperature

\section{Performance of air cooled system on heatsink and reflector temperature}

In this section, an attempt is made to compare the simulated results of a heat sink with the experimental data. Figure 11 shows the comparison of simulated and measured temperature at various test points on the heat sink. This analysis gives us the accuracy of the simulation and in future various types of heatsink configuration with HPLED array in head lamps can be evaluated using simulation. For simulation ANSYS package is used in this study[20]. The average deviation in simulated temperature at various points on the heatsink is found to be a maximum of around $6 \%$. Based on the actual measured temperature, it is observed that simulated temperature is higher than the actual temperature at most of the points. This may be due to variation material properties[21], variation in humidity and temperature of ambient air. Conventional headlamp assemblies are prone to heat damage as it is a closed enclosure and cooling mode is only by means of conduction and radiation.

When the engine compartment temperature increases at certain conditions as mentioned earlier, cooling the headlamp assembly becomes a challenge. Headlamp reflectors are the one which gets damaged first due to heat. As halogen bulbs radiate more heat than HPLEDs, the inner periphery of the reflectors of the headlamp reach a maximum temperature of $75^{\circ} \mathrm{C}$ with halogen bulbs. The maximum temperature reached with HPLED is around $32^{\circ}$ C. 


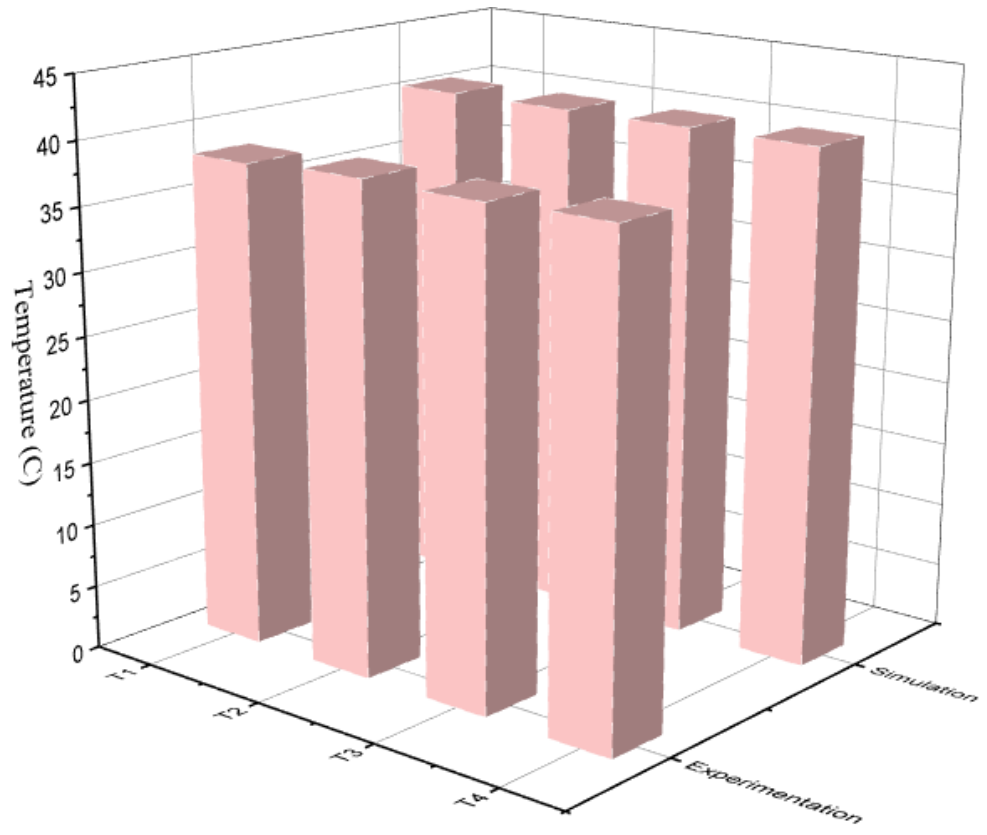

Figure 11. Temperature measurement on heatsink compared with experiment and simulation

Figure 12 shows the comparison of reflector surface temperature with a halogen bulb and HPLED. It is also observed from the experimental trials that the reflector inner periphery temperature is lower than the heatsink temperature when operated with HPLED. By comparing to the earlier studies, the proposed model is simpler and experimented in real time condition. Most of the earlier studies are simulated and not correlated the change in light intensity along with the junction temperature. Also the proposed model experimented with reflector temperature were not considered in earlier studies.

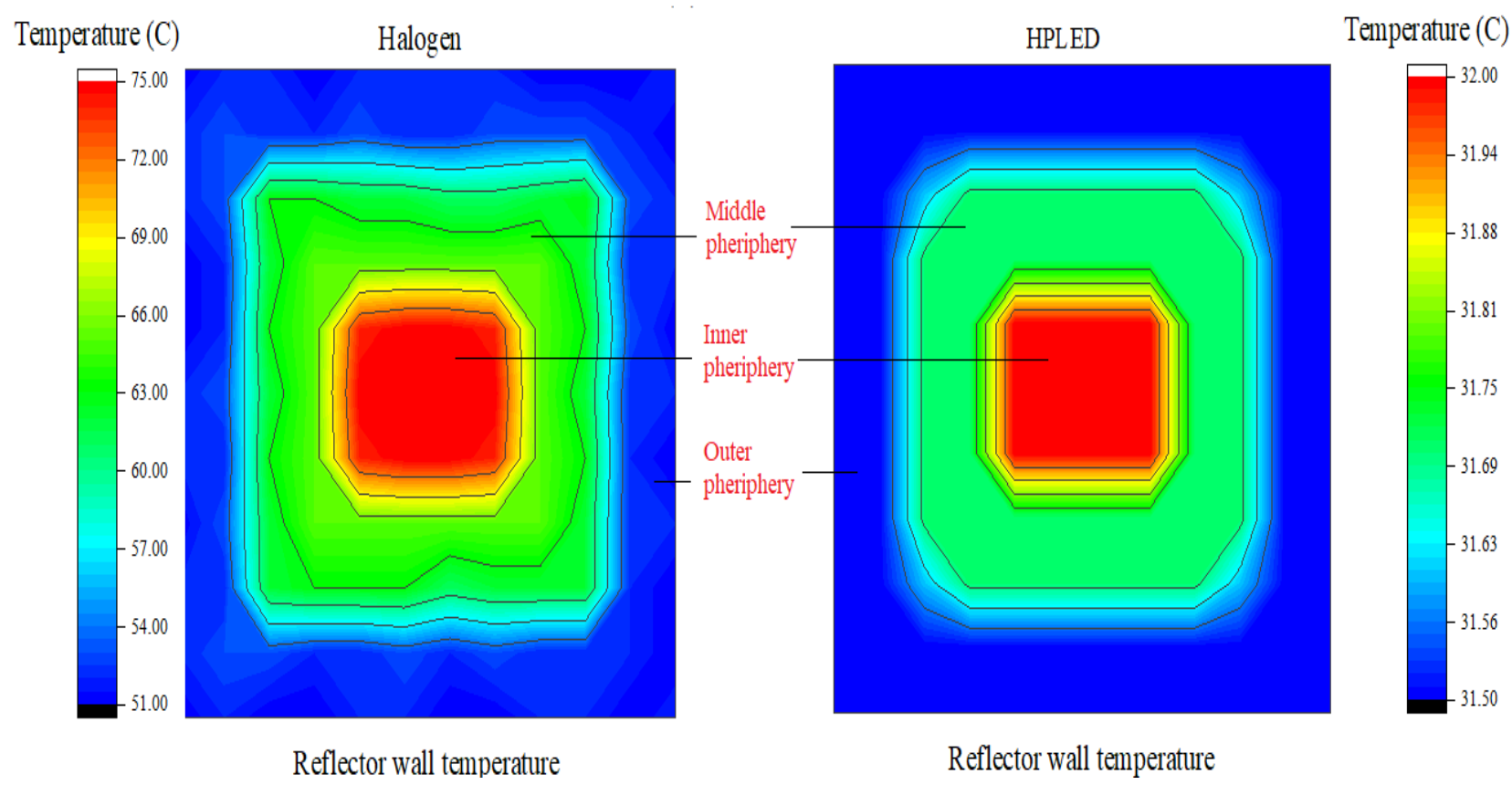

Figure 12. Temperature measurement on headlamp reflector in the inner and outer periphery 


\section{CONCLUSION}

The performance and life of the HPLEDs can be improved by maintaining the HPLED junction temperature below $85^{\circ} \mathrm{C}$. This is possible only when a proper cooling system is used along with HPLED. When the junction temperature is maintained below $85^{\circ} \mathrm{C}$, the average life span of the HPLED will be in the range of 50000 to 60000 hours and HPLED operates at its maximum luminous efficacy. It is possible to save energy and reduce the Green House gas emission with HPLEDs as its efficiency is better than halogen and Xenon lamps. HPLEDs radiate less heat and emit higher intensity white light that improves visibility during the night. Based on the vigorous tests conducted the following conclusion statements are drawn.

- From the observations it is found that, the junction temperature was found as $116^{\circ} \mathrm{C}$ without a cooling fan and the temperature on the heatsink corners are around $40.4^{\circ} \mathrm{C}$. Further the temperature will reduce to near room temperature on the edge of the reflectors while using the proposed design.

- With the proposed HPLED cooling system, the HPLED was tested under steady state and rated power conditions. Maximum luminous light output is achieved when the fan is operated with an air flow rate of $1.9 \mathrm{~m} / \mathrm{s}$ and junction temperature is maintained around $85^{\circ} \mathrm{C}$. With a proper cooling system, HPLED reflector temperature is reduced by $49.19 \%$ when compared with the results of halogen bulb reflector. Based on the correlated color temperature, the light output from the headlamp is considered as natural white

- From the aspects of size, weight and costs, air cooled systems are simple as it doesn't require storage of liquid. With a compact fan, maintenance of the cooling system is easier and cheaper.

- At present, the automotive industries are trying to incorporate a laser based lighting system at a lower cost. The efficiency of the laser lighting system is about $40 \%$. The laser lighting system requires a more complicated thermal management system than HPLEDs.

\section{Nomenclature}

$\begin{array}{ll}\text { CCT } & \text { Correlated Color Temperature, } \mathrm{K} \\ \text { HPLED } & \text { High Power Light Emitting Diode } \\ \mathrm{I}_{\text {forward }} & \text { forward current, Amps } \\ \mathrm{Re} & \text { Reynolds number } \\ \mathrm{R}_{\text {jn-sp }} & \text { junction to solder point thermal resistance, }{ }^{\circ} \mathrm{C} / \mathrm{W} \\ \mathrm{R}_{\text {sp-pcbd }} & \text { solder point to printed circuit board thermal resistance, }{ }^{\circ} \mathrm{C} / \mathrm{W} \\ \mathrm{R}_{\text {pcbd-timl }} & \text { printed circuit board to thermal interface material thermal resistance, }{ }^{\circ} \mathrm{C} / \mathrm{W} \\ \mathrm{R}_{\text {timl-hs }} & \text { thermal interface material to heatsink thermal resistance, }{ }^{\circ} \mathrm{C} / \mathrm{W} \\ \mathrm{R}_{\text {hs-amb }} & \text { heatsink to ambient thermal resistance, }{ }^{\circ} \mathrm{C} / \mathrm{W} \\ \mathrm{R}_{\text {thcomp }} & \text { total thermal resistance of component, }{ }^{\circ} \mathrm{C} / \mathrm{W} \\ \mathrm{T}_{\text {jn }}-\mathrm{T}_{\text {sp }} & \text { junction to solder point temperature, }{ }^{\circ} \mathrm{C} \\ \mathrm{T}_{\text {sp }}-\mathrm{T}_{\text {pcbd }} & \text { solder point to printed circuit board temperature, }{ }^{\circ} \mathrm{C} \\ \mathrm{T}_{\text {pcbd }}-\mathrm{T}_{\text {timl }} & \text { printed circuit board to thermal interface material temperature, }{ }^{\circ} \mathrm{C} \\ \mathrm{T}_{\text {timl }}-\mathrm{T}_{\text {hs }} & \text { thermal interface material to heatsink temperature, }{ }^{\circ} \mathrm{C} \\ \mathrm{T}_{\text {hs }}-\mathrm{T}_{\text {amb }} & \text { heatsink to ambient temperature, }{ }^{\circ} \mathrm{C} \\ \mathrm{P}_{\text {total }} & \text { total thermal power, Watts } \\ \mathrm{V}_{\text {forward }} & \text { forward voltage, Volts } \\ \mathrm{v} & \text { Velocity of air, } \mathrm{m} / \mathrm{s} \\ \rho & \text { Density of air, kg/m } \\ \mathrm{V} & \text { Dynamic viscosity of air, Ns } / \mathrm{m}^{2}\end{array}$


Journal of Thermal Engineering, Research Article, Vol. 6, No. 6, Special Issue 12, pp. 354-368, December, 2020

\section{REFERENCES}

[1] Sousa JMM, Vogado J, Costa M, Bensler H, Freek C, Heath D. An experimental investigation of fluid flow and wall temperature distributions in an automotive headlight. International Journal of Heat and Fluid Flow 2005;26:709-21. https://doi.org/10.1016/j.ijheatfluidflow.2005.05.003.

[2] Weng CJ. Advanced thermal enhancement and management of LED packages. International Communications in Heat and Mass Transfer 2009;36:245-8. https://doi.org/10.1016/j.icheatmasstransfer.2008.11.015.

[3] Tsai MY, Chen CH, Kang CS. Thermal measurements and analyses of low-cost high-power LED packages and their modules. Microelectronics Reliability 2012;52:845-54. https://doi.org/10.1016/j.microrel.2011.04.008.

[4] Jung ED, Lee YL. Study on the development of LED headlamps for used cars. Transactions on Electrical and Electronic Materials 2014;15:270-4. https://doi.org/10.4313/TEEM.2014.15.5.270.

[5] Kaya M. Experimental Study on Active Cooling Systems Used for Thermal Management of High-Power Multichip Light-Emitting Diodes. Scientific World Journal 2014;. http://dx.doi.org/10.1155/2014/563805.

[6] Wang J, Zhao X, Cai Y, Zhang C, Bao W. Experimental study on the thermal management of high-power LED headlight cooling device integrated with thermoelectric cooler package. Energy Conversion and Management 2015;101:532-40. https://doi.org/10.1016/j.enconman.2015.05.040.

[7] Sökmen KF, Yürüklü E, Yamankaradeniz N. Computational thermal analysis of cylindrical fin design parameters and a new methodology for defining fin structure in LED automobile headlamp cooling applications. Applied Thermal Engineering 2016;94:534-42.

https://doi.org/10.1016/j.applthermaleng.2015.10.069.

[8] Niculina BD, Paul S, Cristina M. Fan vs. Passive heat sinks for cooling high power COB-type LEDs. Proceedings of the 9th International Conference on Electronics, Computers and Artificial Intelligence, ECAI 2017 2017;2017-Janua:1-4. https://doi.org/10.1109/ECAI.2017.8166477.

[9] Sufian SF, Fairuz ZM, Zubair M, Abdullah MZ, Mohamed JJ. Thermal analysis of dual piezoelectric fans for cooling multi-LED packages. Microelectronics Reliability 2014;54:1534-43. https://doi.org/10.1016/j.microrel.2014.03.016.

[10] Singh R, Jalilvand A, Goto K, Mashiko K, Saito Y, Mochizuki M. Direct impingement cooling of LED by Piezo fan. 2014 International Conference on Electronics Packaging, ICEP 2014 2014:1-5. https://doi.org/10.1109/ICEP.2014.6826650.

[11] Fu HK, Wang CP, Chiang HC, Chen T Te, Chen CL, Chou PT. Evaluation of temperature distribution of LED module. Microelectronics Reliability 2013;53:554-9. https://doi.org/10.1016/j.microrel.2012.11.009.

[12] Maaspuro M, Tuominen A. Microelectronics Reliability Thermal analysis of LED spot lighting device operating in external natural or forced heat convection. Microelectronics Reliability 2013;53:428-34. https://doi.org/10.1016/j.microrel.2012.10.004.

[13] Wang J, Cai YX, Zhao XJ, Zhang C. Thermal design and simulation of automotive headlamps using white LEDs. Microelectronics Journal 2014;45:249-55. https://doi.org/10.1016/j.mejo.2013.11.011.

[14] Su YF, Yang SY, Hung TY, Lee CC, Chiang KN. Light degradation test and design of thermal performance for high-power light-emitting diodes. Microelectronics Reliability 2012;52:794-803. https://doi.org/10.1016/j.microrel.2011.07.059.

[15] Shih K. LED Junction Temperature Measurement and its Applications to Automotive Lamp Design. SAE Technical Paper 2004. https://doi.org/10.4271/2004-01-0224.

[16] Colaco AM, Kurian CP, Kini SG, Colaco SG, Johny C. Thermal characterization of multicolor LED luminaire. Microelectronics Reliability 2017;78:379-88. https://doi.org/10.1016/j.microrel.2017.04.026.

[17] J. P. Holman. Experimental methods for engineers. 8th ed. McGrawHill; 2012.

[18] Lampio K, Karvinen R. Optimization of convectively cooled heat sinks. Microelectronics Reliability 2017;79:473-9. https://doi.org/10.1016/j.microrel.2017.06.011.

[19] Rammohan A, Kumar Ramesh C. A review on effect of thermal factors on performance of high power light emitting diode (HPLED). Journal of Engineering Science and Technology Review 2016;9:165-76. https://doi.org/10.25103/jestr.094.24.

[20] Dongmei Zhou and Timothy Rau. Thermal design methodology and prediction of heat sink performance. Journal of Thermal Engineering 2016;2:826-36. https://doi.org/10.18186/jte.29129.

[21] Abu M, Alt V. The Effect of Blowing Direction on Heat Sink Performance. Journal of Thermal Engineering 2018;4:2471-80 2018;4:2471-80. https://doi.org/10.18186/thermal.465695. 